\title{
A Comparative Analysis of the Effect of Seaweed Fertilizers (Liquid \& Paste) and Vermiwash on Seed Germination of Cyamopsis tetragonoloba
}

\author{
K. Chithra ${ }^{1}$, L. Stanley Abraham ${ }^{2 *}$, R. Thirugnanasambandham ${ }^{2}$ and P. Prakash ${ }^{1}$ \\ ${ }^{1}$ Department of Biotechnology, Sathyabama University, Rajiv Gandhi Road, Chennai - 600119, India. \\ ${ }^{2}$ Centre for Ocean Research, Sathyabama University, Rajiv Gandhi Salai, Chennai - 600 119, India.
}

http://dx.doi.org/10.13005/bbra/2137

(Received: 16 February 2016; accepted: 20 April 2016)

\begin{abstract}
The present investigation has been made to compare "the effect of seaweed fertilizers and vermiwash on seed germination of Cyamopsis tetragonoloba (Cluster bean or Guar)". Seeds were soaked in various concentrations $(0.5 \%, 1 \%, 2 \%, 3 \%$ and $5 \%)$ of seaweed fertilizers (liquid \& paste) and vermiwash separately at different time periods (30, 60 and 120 minutes). After 7 days, the seeds were analyzed for their germination capacity, shoot length \& root length. The study infers that seaweed liquid fertilizers with the concentration of $1 \%$ showed maximum seed germination $(100 \%)$ and the optimum shoot and root length was recorded as $6.04 \mathrm{~cm}$ and $3.34 \mathrm{~cm}$ respectively soaking whereas in seaweed paste fertilizers, $3 \%$ showed maximum seed germination $100 \%$ with the shoot \& root length of $6.58 \mathrm{~cm}$ and $3.46 \mathrm{~cm}$ after 120 minutes. Also, the vermiwash with the concentration of $0.5 \%$ showed maximum seed germination $(100 \%)$ and the optimum shoot and root length was recorded as $6.32 \mathrm{~cm}$ and $3.52 \mathrm{~cm}$ respectively after 30 minutes soaking.
\end{abstract}

Key words: Seaweed Fertilizer, Vermiwash, Seed germination,

Cyamopsis tetragonoloba and Plant growth

Nowadays, it is absorbed that the abundant use of chemical fertilizers affects soil \& plants, which causes deleterious effect to human and environment. Recent researches proved that the seaweed fertilizers as bio-inoculants are preferred not only due to their nitrogen, phosphorus, potash contents but also because of the presence of trace elements and metabolites similar to plant growth regulators.

Seaweeds are the macroscopic marine algae grow as attached to the bottom in relatively shallow coastal waters. They found to be utilized in food, cosmetics and Agriculture. Seaweed liquid

\footnotetext{
* To whom all correspondence should be addressed. E-mail: stanleyabraham313@gmail.com
}

fertilizer (SWF (L)) contained macro nutrients $(0.3 \%$ $\mathrm{N}$ (Nitrogen), $0.1 \% \mathrm{P}$ (Phosphorous) $1.0 \% \mathrm{~K}$ (potassium)), trace elements, organic substances like amino acids and plant growth regulators such as auxin, cytokine and gibberellins. Seaweed extract is used as organic bio fertilizer because of its organic micro nutrient, NPK and Natural Growth Hormones content such as Cytokines, Alginic Acid, Mannitol, Gibberellins. Seaweed is used as Plant Growth Promoter for all Kinds of crops. They are also used as manure for agricultural and horticultural crops ${ }^{4}$ due to the presence of minerals, trace elements and plant growth regulators which occur in water soluble form ${ }^{5}$ and enhances the disease resistance in field crops ${ }^{6}$. Hence the present study was conducted to find out the effect of seaweed on the growth of plants. Seaweed 
concentrates are known to cause many beneficial effects on plants as they contain growth promoting hormones (IAA and IBA, Cytokines) trace elements (Fe, $\mathrm{Cu}, \mathrm{Zn}, \mathrm{Co}, \mathrm{Mo}, \mathrm{Mn}$, and $\mathrm{Ni}$ ), vitamins and amino acids ${ }^{2-3}$. observed that the value of seaweeds as fertilizers was not only due to nitrogen, phosphorus and potash content, but also because of the presence of trace elements and metabolites. Liquid extracts obtained from seaweeds are successfully used as foliar sprays for several crops ${ }^{1}$

Vermiwash is a liquid extract, which is collected passing water through a worm culture column. The extract is enriched with nutrients and microorganisms, and applied as a foliar spray for crops. It contains plant growth hormones like auxin and cytokines apart from nitrogen, phosphorus potash and other micro-nutrients. It is the organic fertilizer obtained from units of vermiculture and vermicompost as drainage.

Cyamopsis tetragonoloba belong to the fabaceae family and is distributed all over the world. It grows best in in fertile, medium-textured and sandy loam soils and full sun light. It also grows best in moderate alkaline conditions ( $\mathrm{pH} 7-8$ ) and is tolerant of salinity. Guar as a plant has versatile functions for human and animal nutrition but its gelling-agent-containing seeds (guar gum) are found to be widely used in hydraulic fracturing (oil shale gas) industries. Cluster beans are rich in fibre and low in calories. It contains various vitamins namely vitamin $\mathrm{a}, \mathrm{b}$ and $\mathrm{k}$ and minerals such as potassium, iron and calcium in addition to other nutrients. Cluster beans contain glyconutrients that help in controlling blood sugar levels in the body. They are rich in potassium, which helps in maintaining the blood pressure,increases blood circulation, strengthens bones, lowers the blood levels of bad cholesterol (LDL) and helps in digestion.

Hence this present study focused to gain information on seaweed fertilizer (liquid \& paste) \& vermiwash and also its effect on seed germination of Cyamopsis tetragonoloba.

\section{EXPERIMENTAL}

\section{Materials and Methods}

Cluster bean seed were purchased from the local market \& healthy seeds were selected for this study. Vermiwash was prepared by soaking the vermicompost in water overnight and filtered. The seeds (5 Nos) were soaked in sterile distilled water and treated with various concentrations of Seaweed fertilizers $(0.5 \%, 1 \%, 2 \%, 3 \%$ and $5 \%$ ) for various time intervals (30 min, $60 \mathrm{~min}, 120 \mathrm{~min}$ ). All the treated seeds were placed in sterile petridishes containing a thin layer of wet cotton and covered with wet filter paper. Seed germinated in distilled water was served as a control. The percentage of seed germination, root length and shoot length were recorded after 7 days of sowing and tabulated.

\section{RESULTSAND DISCUSSION}

In the present study, effect of vermiwash, seaweed fertilizer treated cluster bean seeds showed significant results over untreated seeds and are presented in the (Table 1) which shows the percentage of seed germination over control in different concentrations of vermiwash \& seaweed fertilizer.

* $\quad$ Among the treatments, maximum seed germination was observed in $3 \%$ of seaweed paste, $1 \%$ of seaweed liquid in 120 minutes \& $0.5 \%$ of

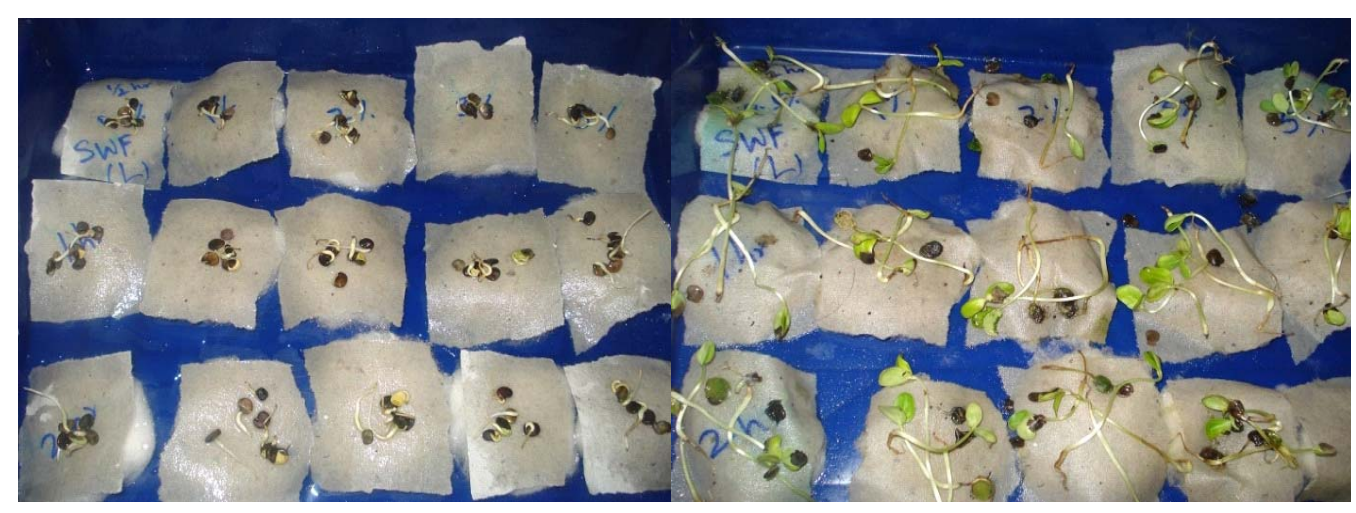

Fig. 1. Germination of Cyamopsis tetragonoloba seeds in seaweed liquid fertilizers 
CHITHRA et al., Biosci., Biotech. Res. Asia, Vol. 13(2), 1089-1093 (2016)

Table 1. Effect of seaweed fertilizer (paste \& liquid) and vermiwash on seed germination

\begin{tabular}{|c|c|c|c|c|c|c|}
\hline $\begin{array}{l}\text { Seed } \\
\text { Soaking } \\
\text { time } \\
\text { (minutes) }\end{array}$ & $\begin{array}{c}\text { Seaweed paste } \\
\text { concentration } \\
(\%)\end{array}$ & $\begin{array}{c}\text { Seed } \\
\text { Germination } \\
(\%)\end{array}$ & $\begin{array}{c}\text { Seaweed } \\
\text { Liquid } \\
\text { concentration } \\
(\%)\end{array}$ & $\begin{array}{c}\text { Seed } \\
\text { germination } \\
(\%)\end{array}$ & $\begin{array}{l}\text { Vermi wash } \\
\text { concentration }\end{array}$ & $\begin{array}{c}\text { Seed } \\
\text { germination } \\
(\%)\end{array}$ \\
\hline \multirow[t]{5}{*}{30} & 0.5 & 60 & 0.5 & 80 & 0.5 & 100 \\
\hline & 1 & 60 & 1 & 80 & 1 & 80 \\
\hline & 2 & 80 & 2 & 80 & 2 & 80 \\
\hline & 3 & 80 & 3 & 80 & 3 & 80 \\
\hline & 5 & 80 & 5 & 80 & 5 & 80 \\
\hline \multirow[t]{5}{*}{60} & 0.5 & 80 & 0.5 & 80 & 0.5 & 80 \\
\hline & 1 & 80 & 1 & 80 & 1 & 80 \\
\hline & 2 & 80 & 2 & 80 & 2 & 80 \\
\hline & 3 & 80 & 3 & 80 & 3 & 80 \\
\hline & 5 & 80 & 5 & 80 & 5 & 80 \\
\hline \multirow[t]{5}{*}{120} & 0.5 & 80 & 0.5 & 60 & 0.5 & 80 \\
\hline & 1 & 80 & 1 & 100 & 1 & 80 \\
\hline & 2 & 80 & 2 & 80 & 2 & 80 \\
\hline & 3 & 100 & 3 & 80 & 3 & 80 \\
\hline & 5 & 80 & 5 & 80 & 5 & 80 \\
\hline Control & Soaked in water & 60 & & & & \\
\hline
\end{tabular}

Values are Mean \pm Standard Deviation

Table 2. Average shoot length after treatment of different concentrations of seaweed paste fertilizer, seaweed liquid fertilizer \& vermiwash

\begin{tabular}{|c|c|c|c|c|c|c|}
\hline $\begin{array}{l}\text { Seed } \\
\text { Soaking } \\
\text { time } \\
\text { (minutes) }\end{array}$ & $\begin{array}{c}\text { Seaweed paste } \\
\text { concentration } \\
\text { (\%) }\end{array}$ & $\begin{array}{l}\text { Shoot } \\
\text { Length } \\
(\text { in } \mathrm{cm})\end{array}$ & $\begin{array}{c}\text { Seaweed } \\
\text { Liquid } \\
\text { concentration } \\
\text { (\%) }\end{array}$ & $\begin{array}{l}\text { Shoot } \\
\text { Length } \\
\text { (in cm) }\end{array}$ & $\begin{array}{c}\text { Vermi wash } \\
\text { concentration } \\
\text { (\%) }\end{array}$ & $\begin{array}{l}\text { Shoot } \\
\text { Length } \\
(\text { in } \mathrm{cm})\end{array}$ \\
\hline \multicolumn{7}{|l|}{ Control } \\
\hline \multirow[t]{5}{*}{30} & 0.5 & $5.88 \pm 0.26$ & 0.5 & $4.94 \pm 0.29$ & 0.5 & $6.32 \pm 0.37$ \\
\hline & 1 & $5.60 \pm 0.36$ & 1 & $5.14 \pm 0.77$ & 1 & $5.16 \pm 0.48$ \\
\hline & 2 & $5.24 \pm 0.41$ & 2 & $5.74 \pm 0.22$ & 2 & $4.76 \pm 0.10$ \\
\hline & 3 & $5.50 \pm 0.18$ & 3 & $5.78 \pm 0.17$ & 3 & $5.54 \pm 0.44$ \\
\hline & 5 & $5.76 \pm 0.35$ & 5 & $5.04 \pm 0.19$ & 5 & $5.68 \pm 0.20$ \\
\hline \multirow[t]{5}{*}{60} & 0.5 & $5.06 \pm 0.42$ & 0.5 & $5 \pm 0.25$ & 0.5 & $5.36 \pm 0.42$ \\
\hline & 1 & $5.22 \pm 0.56$ & 1 & $4.92 \pm 0.32$ & 1 & $5.12 \pm 0.23$ \\
\hline & 2 & $5.84 \pm 0.16$ & 2 & $5.24 \pm 0.36$ & 2 & $5.84 \pm 0.30$ \\
\hline & 3 & $5.14 \pm 0.42$ & 3 & $5.58 \pm 0.13$ & 3 & $5.60 \pm 0.18$ \\
\hline & 5 & $5.94 \pm 0.19$ & 5 & $5.84 \pm 0.24$ & 5 & $5.13 \pm 0.35$ \\
\hline \multirow[t]{5}{*}{120} & 0.5 & $4.46 \pm 0.37$ & 0.5 & $5.12 \pm 0.55$ & 0.5 & $5.12 \pm 0.82$ \\
\hline & 1 & $5.16 \pm 0.57$ & 1 & $6.04 \pm 0.19$ & 1 & $5.34 \pm 0.57$ \\
\hline & 2 & $5.26 \pm 0.21$ & 2 & $5.24 \pm 0.36$ & 2 & $5.66 \pm 0.27$ \\
\hline & 3 & $6.58 \pm 0.28$ & 3 & $5.70 \pm 0.42$ & 3 & $5.24 \pm 0.67$ \\
\hline & 5 & $5.54 \pm 0.22$ & 5 & $5.84 \pm 0.24$ & 5 & $5.44 \pm 0.52$ \\
\hline
\end{tabular}

Values are Mean \pm Standard Deviation 
Table 3. Average root length after treatment of different concentrations of seaweed paste fertilizer, seaweed liquid fertilizer \& vermiwash

\begin{tabular}{|c|c|c|c|c|c|c|}
\hline $\begin{array}{l}\text { Seed } \\
\text { Soaking } \\
\text { time } \\
\text { (minutes) }\end{array}$ & $\begin{array}{c}\text { Seaweed paste } \\
\text { concentration } \\
(\%)\end{array}$ & $\begin{array}{l}\text { Root } \\
\text { Length } \\
\text { (in cm) }\end{array}$ & $\begin{array}{c}\text { Seaweed } \\
\text { Liquid } \\
\text { concentration(\%) }\end{array}$ & $\begin{array}{l}\text { Root Length } \\
\quad \text { (in } \mathrm{cm})\end{array}$ & $\begin{array}{l}\text { Vermi wash } \\
\text { concentration } \\
\text { (\%) }\end{array}$ & $\begin{array}{l}\text { Root Length } \\
\quad \text { (in } \mathrm{cm} \text { ) }\end{array}$ \\
\hline & Control & $2.45 \pm 0.11$ & & & & \\
\hline \multirow[t]{5}{*}{30} & 0.5 & $2.74 \pm 0.16$ & 0.5 & $2.8 \pm 0.23$ & 0.5 & $3.52 \pm 0.33$ \\
\hline & 1 & $2.06 \pm 1.04$ & 1 & $3.06 \pm 0.23$ & 1 & $2.48 \pm 0.20$ \\
\hline & 2 & $3.12 \pm 0.25$ & 2 & $2.88 \pm 0.53$ & 2 & $2.4 \pm 0.14$ \\
\hline & 3 & $2.84 \pm 026$ & 3 & $2.42 \pm 0.44$ & 3 & $2.58 \pm 0.16$ \\
\hline & 5 & $3.02 \pm 0.40$ & 5 & $3 \pm 0.42$ & 5 & $2.84 \pm 0.14$ \\
\hline \multirow[t]{5}{*}{60} & 0.5 & $2.70 \pm 0.17$ & 0.5 & $2.98 \pm 0.62$ & 0.5 & $2.84 \pm 0.32$ \\
\hline & 1 & $2.5 \pm 0.32$ & 1 & $2.74 \pm 0.22$ & 1 & $2.74 \pm 0.22$ \\
\hline & 2 & $3.3 \pm 0.38$ & 2 & $3.16 \pm 0.39$ & 2 & $2.68 \pm 0.17$ \\
\hline & 3 & $2.66 \pm 0.10$ & 3 & $3.24 \pm 0.29$ & 3 & $2.94 \pm 0.10$ \\
\hline & 5 & $2.98 \pm 0.23$ & 5 & $2.76 \pm 0.36$ & 5 & $2.82 \pm 0.47$ \\
\hline \multirow[t]{5}{*}{120} & 0.5 & $2.68 \pm 0.17$ & 0.5 & $1.34 \pm 1.09$ & 0.5 & $2.74 \pm 0.08$ \\
\hline & 1 & $2.54 \pm 0.15$ & 1 & $3.34 \pm 0.18$ & 1 & $2.5 \pm 0.14$ \\
\hline & 2 & $2.68 \pm 0.19$ & 2 & $3.08 \pm 0.25$ & 2 & $2.66 \pm 0.44$ \\
\hline & 3 & $3.46 \pm 0.19$ & 3 & $3.1 \pm 0.35$ & 3 & $2.14 \pm 0.24$ \\
\hline & 5 & $2.72 \pm 0.20$ & 5 & $1.94 \pm 0.99$ & 5 & $3.04 \pm 0.33$ \\
\hline
\end{tabular}

Values are Mean \pm Standard Deviation

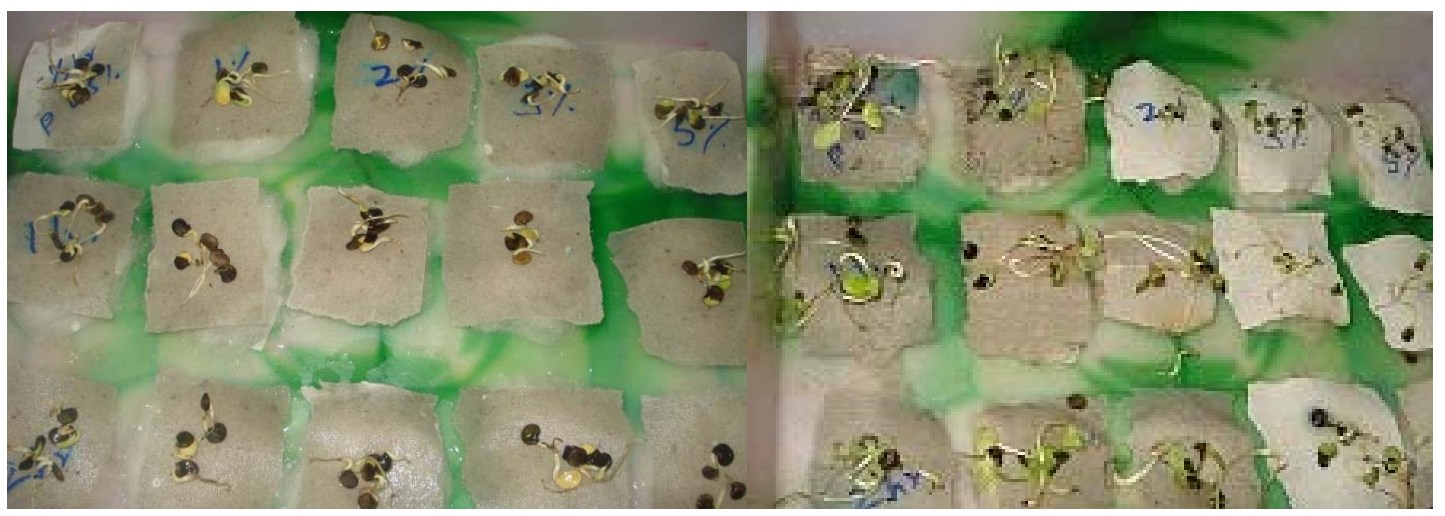

Fig. 2. Germination of Cyamopsis tetragonoloba seeds in seaweed paste fertilizers

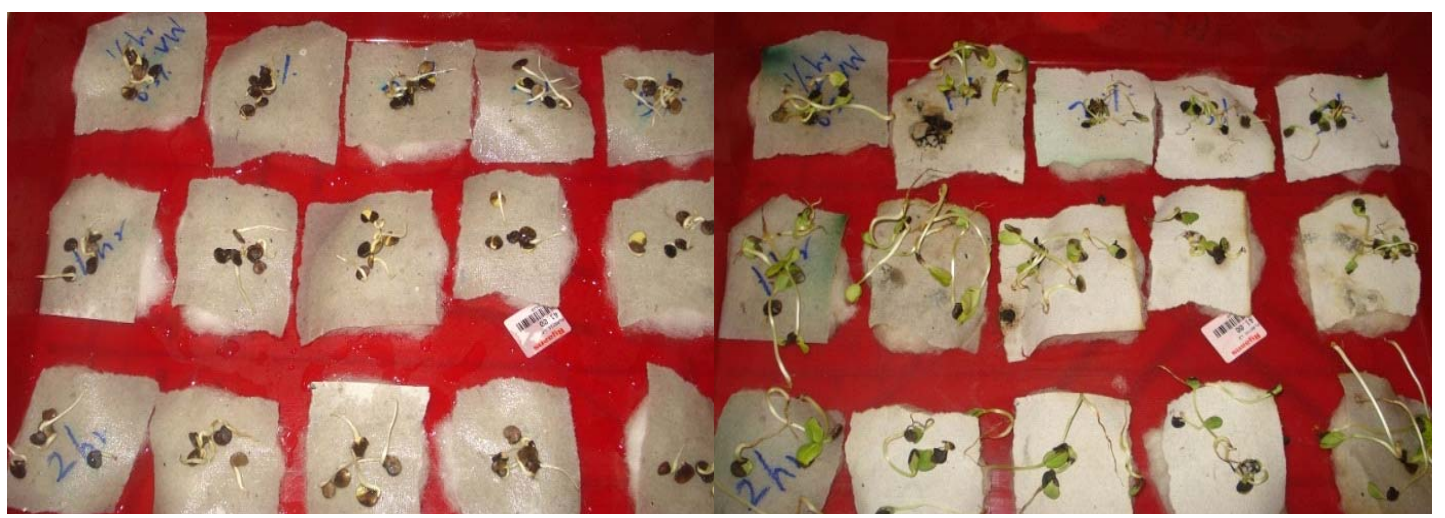

Fig. 3. Germination of Cyamopsis tetragonoloba seeds in vermiwash 
vermiwash concentration in 30 minutes. Their respective optimum shoot lengths are $6.58 \pm 0.28$ $\mathrm{cm}, 6.04 \pm 0.19 \mathrm{~cm}, 6.32 \pm 0.37 \mathrm{~cm}$ and their respective optimum root lengths are $3.46 \pm 0.19$ $\mathrm{cm}, 3.34 \pm 0.18 \mathrm{~cm}, 3.52 \pm 0.33 \mathrm{~cm}$.

Vermiwash a potent organic fertilizer plays a vital role in the plant growth and development; contribute to increased initiation of root, root growth, plant development, promotion growth rate and improvement in crop production increases the soil organic matter and increase in nutrient content of the crop produce ${ }^{4}$. The growth enhancing potential of seaweeds might be attributed by the presence of macro and micronutrients present in high concentration, when applied as foliar spray enhances the root formation and fast growth in plants ${ }^{5}$.

\section{CONCLUSION}

Thus the present study reveals the required concentration of $3 \%$ of seaweed paste, $1 \%$ of seaweed liquid in 120 minutes \& $0.5 \%$ of vermiwash concentration in 30 minutes for seed germination and seedling growth have effective root length and shoots length.

\section{ACKNOWLEDGEMENTS}

The authors are grateful to the management of Sathyabama University for providing laboratory facilities, support and encouragement.

\section{REFERENCES}

1. Bokil, KK; VC Mehta; DS Datar,Phykos, 1974; 13(1): 1-5. E Booth, In the Proceedings of the International Seaweed Symposium,1969; 6: 655662.

2. SB Challen; JC Hemingway, 5th Ind. Seaweed Symp, 1965; 359-367.

3. VJ Chapman; DJ Chapman, Seaweeds And Their Uses, Third Editions, Chapman and Hall, New York, 1980; 304.

4. Kale, R.D. In earthworm s ecology. Edwards, C.A (Ed.) CRC Press LLC. BOCCA. Raton, Florida. 1998; 355-376.

5. Maheswarappa H.P., Nanjappa.,HV., HV and Hegde MR. Annals of Agricultural Research 1999; 20(3): 318-323.

6. M Moller; ML Smith, Journal of Plant Physiology;1998; 153: 658-663.

7. FN Verkleij, A Review Biological Agriculture and Horticulture,1992; 8: 309-324. 